\title{
On-Line Estimation of Biomass Through pH Control Analysis in Aerobic Yeast Fermentation Systems
}

\author{
Antonio Vicente, ${ }^{1}$ J uan I. Castrillo, ${ }^{2}$ J osé A. Teixeira, ${ }^{1}$ Unai Ugalde ${ }^{2}$ \\ ${ }^{1}$ Departamento de Engenharia Biológica, Universidade do Minho, Campus \\ de Gualtar, 4709 Braga codex, Portugal \\ ${ }^{2}$ Unidad de Bioquímica, Departamento de Química Aplicada, Facultad de \\ Ciencias Quimicas, Universidad del País Vasco, P.O. Box 1072, 20080 San \\ Sebastián, Spain; telephone: +34 43 448000; fax: +34 43 212236; e-mail: \\ qppugmau@sq.ehu.es
}

Received 2 May 1997; accepted 3 December 1997

\begin{abstract}
The amount of acid or base consumed in yeast cultures has been recently assigned to the pathway of nitrogen assimilation under respiratory conditions with no contribution by carbon metabolism (Castrillo et al., 1995). In this investigation, experiments under respirofermentative conditions have shown that production or consumption of ethanol does not contribute significantly to the specific rate of proton production $\left(\mathrm{qH}^{+}\right)$, thus extending the previously obtained relationships for all aerobic conditions in which other major acid/base contributions are not involved. Tests in batch and chemostat culture confirm the validity of $\mathrm{qH}^{+}$as a formal control parameter in aerobic fermentations. (c) 1998 J ohn Wiley \& Sons, Inc. Biotechnol Bioeng 58: 445-450, 1998.
\end{abstract}

Keywords: on-line control; pH control; growth monitoring; proton titration; yeast

\section{INTRODUCTION}

Biomass determination is a basic parameter in fermentation processes. Therefore, simple and reliable on-line estimation procedures are highly desirable, particularly in fermentation processes using Saccharomyces cerevisiae (Fiechter et al., 1987; Larsson et al., 1993; Postma et al., 1989; Verduyn et al., 1992), which is widely used in industry as a source of a variety of products (van Gulik and Heijnen, 1995; Ohta et al., 1993; Sousa et al., 1994).

Experimental evidence of the existence of a direct relationship between proton production and growth has been presented in the past (Huth et al., 1990a,b,c; Roos and Luckner, 1984) and the determination of the equivalents of acid or base consumed by the culture per unit time has been a widely used parameter for on-line control processes (Ishizaki et al., 1994; Iversen et al., 1994; Pons et al., 1989; San and Stephanopoulos, 1984; Shioya, 1989; Siano, 1995). Nevertheless, the majority of studies have been restricted to the establishment of empirical relations, naturally circum-

Correspondence to: Unai Ugalde

Contract grant sponsors: Junta Nacional de Investigação Científica e Tecnológica; Gobierno Vasco (Departamento de Educación, Universidades e Investigación); Ministerio de Educación y Ciencia-Acciones Integradas scribed to the systems studied while the physiological basis of the models proposed remained unclear.

Many studies on changes in medium $\mathrm{pH}$ associated with growth processes pointed to metabolic activity as the principal cause of medium proton exchange (Huth et al., 1990a,b,c; Kotyk, 1989; Sigler and Höfer, 1991). This fact was confirmed in a recent study in which, after accurate determination of the specific rate of proton production or consumption by the culture $\left(\mathrm{qH}^{+}, \mathrm{mmol}^{-1} \mathrm{~h}^{-1} \mathrm{gbiom}^{-1}\right)$, the nitrogen assimilation pathway was certified as the main contributing pathway under aerobic conditions and respiratory metabolism (Castrillo et al., 1995).

The aim of this article is to verify the applicability of the model described above to those aerobic conditions in which respirofermentative metabolism is involved with production and consumption of ethanol.

\section{MATERIALS AND METHODS}

\section{Determination of the Specific Rate of Proton Production $\left(\mathrm{qH}^{+}\right)$}

The procedure to measure the specific rate of proton production $\left(\mathrm{qH}^{+}\right)$under conditions of negligible formation of acid/base compounds has been described in detail elsewhere (Castrillo et al., 1995). Titration of the volume or weight of the acid/base consumed during a given time, allows for the accurate determination of the specific rate of proton production/consumption $\left(\mathrm{qH}^{+}\right)$by the cells, through the application of mass balance for protons in the reactor medium.

\section{Detection of Lateral Reactions Which Interfere with $\mathbf{q H}^{+}$Determination}

Utilization of complex media or culture conditions favorable to the appearance of ammonia [e.g., degradation of the nitrogen compounds from the medium, or metabolic imbalances resulting in ammonia extrusion from the cells; Phaff et al., (1978)] may lead to undesired acid/base contributions 
affecting the accurate determination of $\mathrm{qH}^{+}$. These contributions can be precisely quantified in experiments using organic nitrogen sources (i.e., urea) by means of the following steps: (1) Formulation of the mass balance for ammonia in the reactor medium; and (2) determination of the specific rate of ammonia generation $\left(q \mathrm{NH}_{3}\right.$, meq $\left.\mathrm{h}^{-1} \mathrm{~g}^{-1}\right)$.

General mass balance for $\mathrm{NH}_{3}$ in the reactor volume:

$V d\left[N_{3}\right] / d t=F_{L}\left(\left[N_{3}\right]_{i}-\left[N_{3}\right]_{o}\right)+F_{N H 3} \quad[=]$ eq h $^{-1}$

where $V$ is the volume of the culture (1); $F_{L}$ is the liquid flux $\left(1 h^{-1}\right)$ for continuous and semicontinuous cultures, $\left[\mathrm{NH}_{3}\right]_{x}$ is the ammonia concentration in the input $(i)$ and output $(o)$ medium $\left(e q 1^{-1}\right)$ and $F_{N_{3}}$ is the net rate of ammonia generation $\left(e q h^{-1}\right)$.

For the different possible configurations (chemostat, fedbatch, batch), determination of either the ammonia concentration in the input and output medium, or the magnitude of the accumulation $\left(d\left[\mathrm{NH}_{3}\right] / d t\right)$ allows for the determination of $F_{N H_{3}}$. The net rate of ammonia generation can be expressed as $F_{\mathrm{NH}_{3}}=(1 / 1000) q \mathrm{NH}_{3} \cdot X \cdot V$, where $X$ is the biomass concentration $\left(\mathrm{g} \mathrm{L}^{-1}\right)$. Thus, $q \mathrm{NH}_{3}$ can be formulated as:

$$
q N H_{3}=(1000 / V) \cdot\left(F_{N H 3}\right) / X \quad[=] \mathrm{meq} \mathrm{h}^{-1} \mathrm{~g}^{-1}
$$

Each equivalent of ammonia appearing in the reactor volume (net generation) will consume a proton equivalent from the medium, which will lead to an extra basic contribution ( $\mathrm{qH}^{+}$underestimation). Therefore, the specific correction in $\mathrm{qH}^{+}$, applicable under conditions in which the appearance of ammonia in lateral reactions is favored, can be expressed as:

$$
q H^{+}{ }_{\text {real }}=q H_{\text {measured }}^{+}+q \mathrm{NH}_{3} \quad[=] \text { meq } \mathrm{h}^{-1} \mathrm{~g}^{-1}
$$

where $\mathrm{qH}^{+}$measured is the specific rate of proton production determined as above (Castrillo et al., 1995). Therefore, the application of equation (3) yields $\mathrm{qH}^{+}$values which can be referred to any other physiological parameter.

When ammonium salts were used as nitrogen source the contribution of ammonia generation by lateral reactions (i.e., oxidative deamination of aminoacids) was considered negligible (see Results and Discussion).

\section{Preparation of the Chemostat Culture}

The culture medium (adapted from Fiechter et al., 1987) consisted of glucose $\left(30 \mathrm{~g} \cdot \mathrm{L}^{-1}\right)$ or ethanol $\left(10 \mathrm{~g} \cdot \mathrm{L}^{-1}\right)$ as carbon source, urea $\left(3.6 \mathrm{~g} \cdot \mathrm{L}^{-1}\right)$, yeast extract $\left(3.0 \mathrm{~g} \cdot \mathrm{L}^{-1}\right)$; $\mathrm{KH}_{2} \mathrm{PO}_{4}\left(3.0 \mathrm{~g} \cdot \mathrm{L}^{-1}, \mathrm{MgSO}_{4} \cdot 7 \mathrm{H}_{2} \mathrm{O}\left(0.45 \mathrm{~g} \cdot \mathrm{L}^{-1}\right), \mathrm{CaCl}_{2}\right.$ $\left(0.23 \mathrm{~g} \cdot \mathrm{L}^{-1}\right), \mathrm{NaCl}\left(0.7 \mathrm{~g} \cdot \mathrm{L}^{-1}\right), \mathrm{FeCl}_{3} \cdot 6 \mathrm{H}_{2} \mathrm{O}(15$ $\left.\mathrm{mg} \cdot \mathrm{L}^{-1}\right), \mathrm{MnSO}_{4} \cdot \mathrm{H}_{2} \mathrm{O}\left(16 \mathrm{mg} \cdot \mathrm{L}^{-1}\right), \mathrm{ZnSO}_{4} \cdot 7 \mathrm{H}_{2} \mathrm{O}(9.0$ $\left.\mathrm{mg} \cdot \mathrm{L}^{-1}\right), \mathrm{CuSO}_{4} \cdot 5 \mathrm{H}_{2} \mathrm{O}\left(2.4 \mathrm{mg} \cdot \mathrm{L}^{-1}\right) \mathrm{NaMoO}_{4} \cdot 2 \mathrm{H}_{2} \mathrm{O}$ $\left(4.0 \mathrm{mg} \cdot \mathrm{L}^{-1}\right), \mathrm{CoCl}_{2} \cdot 6 \mathrm{H}_{2} \mathrm{O}\left(0.3 \mathrm{mg} \cdot \mathrm{L}^{-1}\right)$, meso-inositol $\left(60 \mathrm{mg} \cdot \mathrm{L}^{-1}\right)$, Ca-pantotenate $\left(30 \mathrm{mg} \cdot \mathrm{L}^{-1}\right)$, nicotinic acid $\left(6.0 \mathrm{mg} \cdot \mathrm{L}^{-1}\right)$, thiamine hydrochloride $\left(6.0 \mathrm{mg} \cdot \mathrm{L}^{-1}\right)$, pyridoxine hydrochloride $\left(1.5 \mathrm{mg} \cdot \mathrm{L}^{-1}\right)$, d-biotin $(0.1$ $\left.\mathrm{mg} \cdot \mathrm{L}^{-1}\right)$. The $\mathrm{pH}$ of the medium was aseptically adjusted to 4.0 immediately before use. Sterilization was performed by autoclaving $\left(120^{\circ} \mathrm{C}, 1.2 \mathrm{bar}, 40 \mathrm{~min}\right)$ except for urea and vitamins, which were sterilized by filtration through 0.45 $\mu \mathrm{m}$-pore sterile filters (Millipore, USA) and ethanol, which was added immediately before use.

Freshly prepared (6 d) agar slope cultures of Saccharomyces cerevisiae CBS 7336 (ATCC 32167), in Y.M. medium (Difco, $2 \% \mathrm{w} / \mathrm{v}$ ) at $4^{\circ} \mathrm{C}$ were used to inoculate $250 \mathrm{~mL}$ Erlenmeyer flasks containing $100 \mathrm{~mL}$ of medium. These were incubated at $30^{\circ} \mathrm{C}, 60$ cycles $\cdot \mathrm{min}^{-1}$ for $12 \mathrm{~h}$ and then used to inoculate a $2 \mathrm{~L}$ sterile glass bioreactor containing 1.5 $\mathrm{L}$ of medium. The aeration rate was set at 2 v.v.m. and the culture was incubated at $30^{\circ} \mathrm{C}$ for $14 \mathrm{~h}$. Finally, this culture was transferred to a sterile $14 \mathrm{~L}$ capacity bioreactor (internal diameter: $22 \mathrm{~cm})$ with temperature $\left(30^{\circ} \mathrm{C}\right)$, agitation $(450$ $\mathrm{rpm}$ ), and $\mathrm{pH}$ (4.00) controls (Chemap, Volketswil, Switzerland). Fresh medium was added at a fixed rate of 10 $\mathrm{mL} \cdot \min ^{-1}$ with a Watson Marlow peristaltic pump (Watson Marlow, Falmouth, UK) until a final volume of $5 \mathrm{~L}$.

\section{Chemostat Culture}

The constant volume (5 L) during chemostat operation was maintained by means of an automatic weight-control accessory associated to the main bioreactor. The temperature was kept at $30^{\circ} \mathrm{C}( \pm 0.1)$ and the $\mathrm{pH}$ at $4.00( \pm 0.01)$ by addition of $3 \mathrm{~N} \mathrm{NaOH}$ or $\mathrm{H}_{2} \mathrm{SO}_{4}$ through Preciflow peristaltic pumps (Lambda, Naters, Switzerland). Aeration was fixed at 1 v.v.m.

The system was then allowed to reach a steady state, determined by the attainment of a constant concentration of biomass, dissolved oxygen, and oxygen and carbon dioxide gas fractions on gas outlet for a minimum period of three residence times (Stafford, 1986). At this point, specific rate of proton production $\left(\mathrm{qH}^{+}\right)$was determined by titration of the volume of acid/base $\left(\mathrm{H}_{2} \mathrm{SO}_{4}\right.$ or $\left.\mathrm{NaOH} 0.2 \mathrm{~N}\right)$ consumed during a given amount of time (Castrillo et al., 1995), and samples were taken for off-line measurements. Another dilution rate was then set in order to reach the next steady state. Two series of aerobic steady states were analyzed: one using glucose and the other using ethanol as the only carbon source, respectively.

\section{Batch Culture}

A batch culture was performed as a test for the applicability of the method in monitoring growth. The ratio $\mathrm{qH}^{+} /$ qbiomass (meq $\mathrm{H}^{+}$meq biomass ${ }^{-1}$ ) was calculated by defining qbiomass as meq biomass $\mathrm{h}^{-1} \mathrm{~g}_{\text {biomass }}{ }^{-1}$ (Castrillo and Ugalde, 1994; Herbert, 1976). The medium composition was similar as above with minor changes: glucose concentration, $12 \mathrm{~g} \cdot \mathrm{L}^{-1}$ (no ethanol), ammonium sulphate, 7.9 $\mathrm{g} \cdot \mathrm{L}^{-1}$ (no urea), $\mathrm{NaOH}$ used for base control (not sulphuric acid). The fermentation took place on the same vessel in batch mode, with a total volume of $6 \mathrm{~L}$, at the same temperature, $\mathrm{pH}$, and aeration conditions as used for the chemostat culture. Also the inoculum was prepared as above. 
Samples were taken in duplicate at regular intervals for off-line measurements.

\section{Biomass Estimation}

For a batch culture using glucose and ammonium sulphate two independent phases (growth on glucose and on ethanol) will be displayed. In each phase, a simple biomass estimation may be carried out:

$$
\begin{aligned}
\operatorname{Biomass}_{(t+\Delta t)}= & \operatorname{Biomass}_{(t)}+\left(\Sigma_{\Delta t} N_{O H^{-}}\right) \cdot Y_{X / H+(\Delta t)} \\
& {[=] \mathrm{g} \mathrm{L}^{-1} }
\end{aligned}
$$

where $N_{\mathrm{OH}^{-}}$are the mequivalents of base consumed by the $\mathrm{pH}$ control system during a time interval $(\Delta t)$, and $Y_{X / H+}(\Delta t)$ the ratio of grams of biomass appeared per mequivalent of proton produced by the culture for this period $(\Delta t)$. This ratio can be expressed as: $Y_{X / H+(\Delta t)}\left(\right.$ meq $\left.\mathrm{H}+\mathrm{g}^{-1}\right)=1 /$ $(\mathrm{qH}+/ \mu)$ with $\mu$ the specific rate of biomass production $\left(\mathrm{h}^{-1}\right)$, or, in terms of qbiomass: $Y_{X / H+(\Delta t)}\left(\right.$ meq $\left.\mathrm{H}+\mathrm{g}^{-1}\right)=$ $(1 / 1000) \cdot\left(M_{x}\right) \cdot(1 /(\mathrm{qH}+/ \mathrm{qbiomass}))$, with $M_{x}$ the molecular weight of biomass when expressed as $\mathrm{CH}_{\mathrm{x}} \mathrm{O}_{\mathrm{y}} \mathrm{N}_{\mathrm{z}}$, either on glucose or ethanol (Castrillo and Ugalde, 1994; Herbert, 1976; Oura, 1972; Sonnleitner and Käppeli, 1986; Verduyn et al., 1991).

\section{Analytical Methods}

Biomass and dissolved oxygen concentration were determined as described by Castrillo and Ugalde (1993). Samples for off-line analysis were drawn, placed on ice, centrifuged and the supernatant was immediately frozen in liquid $\mathrm{N}_{2}$ and stored at $-20^{\circ} \mathrm{C}$.

Ethanol determination and quantitative detection of the possible existence of other fermentation products (acetaldehyde, acetate, glycerol, and other compounds) were carried out by gas chromatography as described by Castrillo and Ugalde (1993). Glucose was quantified by the spectrophotometric method of Miller (1959). Urea and ammonia were determined enzymatically with the Boehringer test kit 542946 (Boehringer Mannheim, Germany).

\section{Statistical Treatment}

All data are the average of at least three measurements. Standard error limits have been omitted for clarity but never exceeded more than $6 \%$ of the presented values; the majority of cases were lower than $3 \%$.

\section{RESULTS AND DISCUSSION}

\section{Influence of Ethanol Production/Consumption on $\mathbf{q H}^{+}$}

To confirm the hypothesis that carbon metabolism is balanced with respect to $\mathrm{qH}^{+}$, under respirofermentative as well as under respiratory conditions, two chemostat cultures were run separately with glucose (a fermentable carbon source), and ethanol (non-fermentable carbon source and the product of respirofermentative metabolism) as carbon source. The experiments were performed with urea as nitrogen source as it eliminates the contribution of nitrogen metabolism to $\mathrm{qH}^{+}$(Castrillo et al., 1995) and therefore, permitting the accurate determination of the influence of carbon metabolism alone on $\mathrm{qH}^{+}$.

Lateral processes which may interfere with the measurements, such as dissimilative hydrolysis of urea into ammonia, oxidative deamination of complex nitrogen compounds from the medium, or cells at the transitions between steady states, or imbalance in nitrogen assimilation through specific nitrogen pathways (Large, 1986; Phaff et al., 1978) all result in measurable changes in the medium concentration of ammonia. Thus, determination of the specific rate of appearance/disappearance of ammonia $\left(q \mathrm{NH}_{3}\right.$, meq $\left.\mathrm{h}^{-1} \mathrm{~g}^{-1}\right)$ in each case, and the application of a specific correction accounting for the contribution of these processes allows for the isolation of the specific rate $\left(\mathrm{qH}^{+}\right)$corresponding to the carbon metabolism. The values of $\mathrm{qH}^{+}$, qethanol, and $\mathrm{ab}-$ solute values of $\mathrm{qH}^{+} / \mathrm{qethanol}$, for a range of increasing dilution rates using glucose and ethanol as carbon sources respectively are presented in Tables I and II (negative signs denote a net consumption of protons). The chosen range of dilution rates led to steady states which covered different physiological conditions, as observed by ethanol production (Table I) and biomass levels (Table II). The absolute values of the ratio $\mathrm{qH}^{+} / \mathrm{qethanol}$ vs. the dilution rate were in all cases below 0.1 meq $\mathrm{H}^{+} \mathrm{h}^{-1} \mathrm{~g}^{-1}$, showing that production or consumption of ethanol does not affect $\mathrm{qH}^{+}$significantly under the range of conditions tested. The obtained results show that respiratory and respirofermentative carbon metabolism have a negligible effect on $\mathrm{qH}^{+}$, and confirm our earlier proposals that carbon metabolism is balanced with respect to $\mathrm{H}^{+}$. This fact, although generally accepted in overall stoichiometric formulations (Stryer, 1995; Verduyn et al., 1991) had not been previously certified at the physiological level under strictly controlled experimental conditions. The pathways of carbon metabolism involved in this study can be summarized as:

$$
\begin{array}{ll}
\mathrm{C}_{6} \mathrm{H}_{12} \mathrm{O}_{6}+6 \mathrm{O}_{2} \rightarrow 6 \mathrm{CO}_{2}+6 \mathrm{H}_{2} \mathrm{O} & \text { (oxidative) } \\
\mathrm{C}_{6} \mathrm{H}_{12} \mathrm{O}_{6} \rightarrow 2 \mathrm{CH}_{3} \mathrm{CH}_{2} \mathrm{OH}+2 \mathrm{CO}_{2} & \text { (oxidoreductive) }
\end{array}
$$

Table I. Specific rates (q) and $\mathrm{qH}+$ /qethanol absolute values for the

\begin{tabular}{|c|c|c|c|c|}
\hline Dilution rate, $\mathrm{D}\left(\mathrm{h}^{-1}\right)$ & 0.13 & 0.17 & 0.23 & 0.38 \\
\hline omass $\left(\mathrm{g} \mathrm{L}^{-1}\right.$ & 11.4 & 9.3 & 8.4 & 8.8 \\
\hline $\mathrm{qNH}_{3}\left(\mathrm{meq} \mathrm{N} \mathrm{h}^{-1}\right.$ gbiom $\left.^{-1}\right)$ & 0.01 & 0.01 & 0.01 & -0.32 \\
\hline qethanol (meq ethanol $\mathrm{h}^{-1}$ gbiom $^{-1}$ ) & 1.0 & 2.5 & 4.4 & 3.9 \\
\hline $\mathrm{qH}^{+}$measured $\left(\right.$meq $\mathrm{H}^{+} \mathrm{h}^{-1}$ gbiom $^{-1}$ ) & 0.02 & 0.04 & 0.04 & 0.08 \\
\hline $\mathrm{qH}^{+}$corrected $\left(\right.$meq $\mathrm{H}^{+} \mathrm{h}^{-1}$ gbiom $^{-1}$ ) & 0.03 & 0.05 & 0.05 & -0.24 \\
\hline $\begin{array}{l}\mid \mathrm{qH}^{+} \text {corrected/qethanol | } \\
\left(\mathrm{meq} \mathrm{H}^{+} \text {meq ethanol }{ }^{-1}\right)\end{array}$ & 0.03 & 0.02 & 0.01 & 0.06 \\
\hline
\end{tabular}
dilution rates used during the chemostat culture with glucose $\left(30 \mathrm{~g} \mathrm{~L}^{-1}\right)$ as carbon source, and urea $\left(3.6 \mathrm{~g} \mathrm{~L}^{-1}\right)$ as nitrogen source. 
Table II. Specific rates (q) and $\mathrm{qH}+/ \mathrm{q} e$ thanol absolute values for the dilution rates used during the chemostat culture with ethanol $\left(10 \mathrm{~g} \mathrm{~L}^{-1}\right)$ as carbon source, and urea $\left(3.6 \mathrm{~g} \mathrm{~L}^{-1}\right)$ as nitrogen source.

\begin{tabular}{|c|c|c|c|c|}
\hline Dilution rate, $\mathrm{D}\left(\mathrm{h}^{-1}\right)$ & 0.11 & 0.16 & 0.24 & 0.33 \\
\hline Biomass $\left(\mathrm{g} \mathrm{L}^{-1}\right)$ & 3.2 & 3.2 & 3.7 & 1.5 \\
\hline $\mathrm{qNH}_{3}\left(\right.$ meq $\mathrm{N} \mathrm{h}^{-1}$ gbiom $\left.^{-1}\right)$ & 0 & 0.02 & -0.30 & -0.80 \\
\hline qethanol (meq ethanol $\mathrm{h}^{-1}$ gbiom $^{-1}$ ) & -3.4 & -5.8 & -10.8 & -7.2 \\
\hline $\mathrm{qH}^{+}$measured (meq $\mathrm{H}^{+} \mathrm{h}^{-1}$ gbiom $^{-1}$ ) & -0.03 & -0.01 & 0.70 & 0.40 \\
\hline $\mathrm{qH}^{+}$corrected $\left(\mathrm{meq} \mathrm{H} \mathrm{H}^{+} \mathrm{h}^{-1} \mathrm{gbiom}^{-1}\right)$ & -0.03 & 0.01 & 0.40 & -0.40 \\
\hline $\mid \mathrm{qH}^{+}$corrected/qethanol $\mid\left(\mathrm{meq} \mathrm{H}^{+}\right.$meq ethanol $\left.{ }^{-1}\right)$ & $8.8 \mathrm{E}^{-3}$ & $1.7 \mathrm{E}^{-3}$ & 0.04 & 0.05 \\
\hline
\end{tabular}

$\mathrm{CH}_{3} \mathrm{CH}_{2} \mathrm{OH}+3 \mathrm{O}_{2} \rightarrow 2 \mathrm{CO}_{2}+3 \mathrm{H}_{2} \mathrm{O}$ (oxidative)

In addition, the results also confirm that the nitrogen assimilation pathway is the main contributing element to the net proton production or consumption in microbial cultures. The previously obtained stoichiometric relationships of $\mathrm{qH}^{+} / \mathrm{qN}$ of $+1,0$, and -1 for ammonium ions, urea, and nitrate respectively (Castrillo et al., 1995) can be extended to all aerobic conditions with negligible presence of other acid/base contributions, and constitute the fundamental metabolic basis by which many fermentation processes can be monitored through the accurate titration of $\mathrm{pH}$ control reagent (Ishizaki et al., 1994; Iversen et al., 1994; Pons et al., 1989; San and Stephanopoulos, 1984; Shioya, 1989; Siano, 1995).

\section{Additional Acid/Base Contributions}

Although the main contributor to the total proton production or consumption is nitrogen assimilation, there are lateral processes which can affect $\mathrm{qH}^{+}$determinations significatively. In this work using urea as nitrogen source, the influence of the appearance of ammonia in the medium was taken into account. Among the different mechanisms which can lead to the presence of ammonia, degradation of nitrogen compounds from the medium may have a significative influence. In this study, spontaneous urea degradation can be considered negligible, as urea was sterilized by filtration, thus avoiding autoclaving (Budavari, 1996). Oxidative deamination of cellular proteins transiently occurring between different steady states, or under conditions of an imbalance in nitrogen assimilation through the specific nitrogen pathways are two more possible causes of ammonia production reported to occur in urease-positive yeasts (e.g., Rhodosporidium) (Phaff et al., 1978). For the case of urease-negative yeasts (e.g., Saccharomyces cerevisiae, Kluyveromyces marxianus) which metabolize urea along the pathway catalyzed by the urea carboxylase and allophanate hydrolase, this effect, although not so extreme, may not be ignored (Large, 1986; Phaff et al., 1978). This type of analysis and $\mathrm{qH}^{+}$corrections may be performed in other cases where other organic nitrogen sources are used.

Under conditions of balanced growth, acetic acid originating from acetaldehyde via the pyruvate decarboxylase reaction (PDC) is channeled either to the Krebs cycle (in the mitochondrion), or to biosynthesis [in the cytoplasm or per- oxisomes (Flikweert et al., 1996; de Jong-Gubbels et al., 1995; Postma et al., 1989)]. Both conversions occur without a net contribution to $\mathrm{qH}^{+}$. In many fermentation conditions however, (e.g., excess sugar supply or oxygen limitation) acetic acid can accumulate and diffuse from the cell leading to a significant increase in $\mathrm{qH}^{+}$which, when used as an on-line control parameter, can result in overestimation of biomass concentration (as an example, production of only $0.6 \mathrm{~g} \mathrm{~L}^{-1}$ would result in $1.2 \mathrm{~g}_{\text {biomass L}} \mathrm{L}^{-1}$ overestimation). Similar effects also apply to fermentation processes involving production/consumption of other acid/base compounds (e.g., organic acids) (Siano, 1995).

\section{A Test System in Batch Culture}

The above-mentioned results and conclusions over the negligible contribution of carbon metabolism to $\mathrm{qH}^{+}$, provide a formal basis for the utilization of $\mathrm{qH}^{+}$as on-line control parameter for monitoring biomass levels in aerobic fermentations, when either respiratory or respirofermentative metabolism prevail, and also extends the validity of this model for a variety of simple and complex carbon sources employed in industrial processes.

The overall material balances, and models applicable on an empirical basis to proton production as an on-line fermentation parameter have been precisely formulated in the past (Chattaway et al., 1992; Cooney et al., 1977; San and Stephanopoulos, 1984; Siano, 1995, and Stephanopoulos, 1986). For this study, we have tested our formal model in a batch fermentation of $S$. cerevisiae, with glucose and ammonium sulphate as respective carbon and nitrogen source, thus using a non-steady state system which, on the other hand represents the most commonly applied form of fermentation.

For a specific organism the amount of nitrogen per unit dry weight depends on different factors such as the carbon source and culture conditions. Despite the variations, within a specific range of conditions, this value can be considered to remain more or less constant, and a mean biomass elemental composition can be formulated (Herbert, 1976; Oura, 1972). As an example, elemental compositions and nitrogen content in biomass reported for $S$. cerevisiae growth on glucose are, $\mathrm{CH}_{1.613} \mathrm{O}_{0.525} \mathrm{~N}_{0.152} \mathrm{P}_{0.010} \mathrm{~S}_{0.001}$ (Oura, 1972); $\mathrm{CH}_{1.760} \mathrm{O}_{0.581} \mathrm{~N}_{0.144}$ (Verduyn et al., 1991; Verduyn, 1992); $\mathrm{CH}_{1.79} \mathrm{O}_{0.57} \mathrm{~N}_{0.15}$ (Castrillo and Ugalde, 
1994; Roels, 1980; Sonnleitner and Käppeli, 1986); and on ethanol, $\mathrm{CH}_{1.66} \mathrm{O}_{0.50} \mathrm{~N}_{0.15}$ (Verduyn et al., 1991). These concepts constitute the basis for the formulation of overall stoichiometric equations for growth, in which biomass composition is generally formulated as $\mathrm{CH}_{\mathrm{x}} \mathrm{O}_{\mathrm{y}} \mathrm{N}_{\mathrm{z}}$, normalized to contain $1 \mathrm{gr}$ atom of $\mathrm{C}$ (or a mol equivalent of biomass) (Castrillo and Ugalde, 1994; Herbert, 1976; Oura, 1972).

The consumption and production rates in the overall reaction for growth on glucose and ammonium salts $\left(a \mathrm{C}_{6} \mathrm{H}_{12} \mathrm{O}_{6}+b \mathrm{NH}_{4}+c \mathrm{O}_{2} \rightarrow \mathrm{CH}_{\mathrm{x}} \mathrm{O}_{\mathrm{y}} \mathrm{N}_{\mathrm{z}}+d \mathrm{H}++e \mathrm{CO}_{2}+\right.$ $\mathrm{fH}_{2} \mathrm{O}$ ) are not independent, but are strictly related by specific stoichiometric relationships (Herbert, 1976; Roels, 1980). Thus, $\mathrm{qH}+/ \mathrm{qN}=d / b ; \mathrm{qN} / \mathrm{qbiomass}=b ; \mathrm{qH}+/$ qbiomass $=d$, and also $b$ equals z (molar content of nitrogen in biomass). Because $\mathrm{qH}+/ \mathrm{qN}$ equals unity when using ammonium salts as nitrogen source as determined previously (Castrillo et al., 1995), then (qH+/qbiomass) $=d=$ $b=\mathrm{z}$. A direct relationship between specific rate of proton production $\left(\mathrm{qH}^{+}\right)$and specific growth rate (qbiomass) is therefore expected, and the values of $\mathrm{qH}+/ \mathrm{q} b i o m a s s$ should give a direct reflection of the nitrogen content in biomass. These relations should also apply to growth on ethanol.

Figure 1A shows the evolution of glucose, biomass, and ethanol concentrations during batch fermentation. The time interval between the 7th and the 9th $\mathrm{h}$ corresponds to the

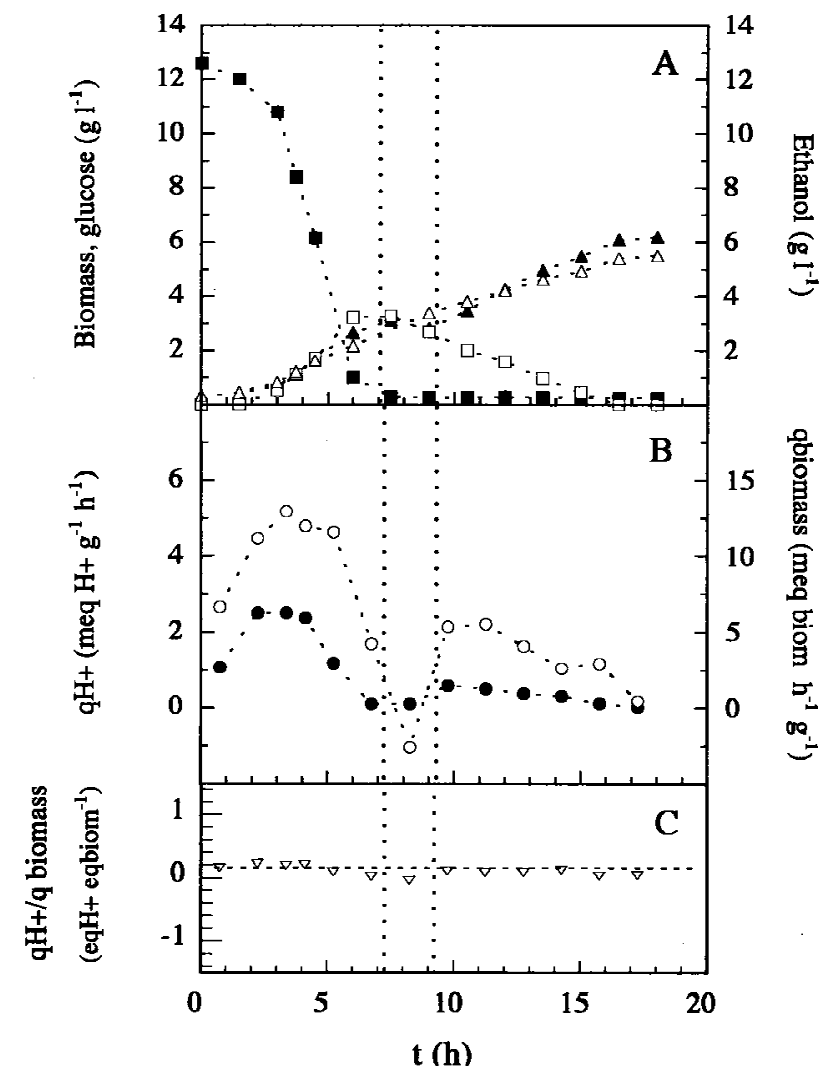

Figure 1. Batch fermentation of Saccharomyces cerevisiae on glucose, with ammonium sulphate as the nitrogen source. (A) Evolution of glucose (-口-), biomass (- $\boldsymbol{\Delta}-)$, ethanol (- $\square-)$ and expected biomass concentration $(-\triangle-)$. (B) Evolution of $\mathrm{qH}^{+}$(-@-), qbiomass (-O-). (C) $\mathrm{qH}^{+} / \mathrm{qbiomass}$ $(-\nabla-)$. period before the start of ethanol consumption by the yeast. Acetate, glycerol, and acetaldehyde were also present but in negligible amounts (results not shown). Figure 1B shows the evolution of $\mathrm{qH}^{+}$and qbiomass, and Figure $1 \mathrm{C}$ the ratio $\mathrm{qH}^{+} / \mathrm{qbiomass}$. This ratio has a constant mean value of 0.15 , which agrees fairly well with the reported values for nitrogen biomass composition for this yeast (Oura, 1972; Roels, 1980; Verduyn et al., 1991) (the negative value at $8 \mathrm{~h}$ is probably due to a slight growth check and deamination which accompanies the switch in carbon source consumption from glucose to ethanol).

By means of these relationships, a simple estimation of the evolution of predicted biomass was conducted (see Materials and Methods), and the results are presented in Figure $1 \mathrm{~A}$, together with the actual biomass measurement. The close match between predicted biomass levels and the measured values, on glucose and on ethanol, strongly supports a negligible contribution of lateral reactions and confirms the validity of $\mathrm{qH}^{+}$as an on-line parameter for monitoring aerobic fermentations.

From the results it may be concluded that respirofermentative carbon metabolism (consumption or production of ethanol) has a negligible effect on the specific rate of proton production $\left(\mathrm{qH}^{+}\right)$. The previously obtained stoichiometric relationships $\mathrm{qH}+/ \mathrm{qN}$ (Castrillo et al., 1995) can therefore be extended to all aerobic conditions in which other acid/ base contributions are negligible. This constitutes the fundamental metabolic basis by which many fermentation processes can be monitored through the accurate titration of the $\mathrm{pH}$ control reagent. Thus, for aerobic cultures with ammonium salts as the nitrogen source, under conditions of minimum formation of either acidic/basic or nitrogen-containing products, the specific rate of proton production $\left(\mathrm{qH}^{+}\right)$is proportional to the rate of biomass production, and can be used to estimate the biomass concentration. Because these relations bare a physiological basis, they may be usefully applied in fermentation control processes as formal rules, appropriate for many different microorganisms which display similar physiological patterns. Moreover, they open the possibility for the determination of new formal relationships, which may extend the applicability of the study to more complex systems (i.e., monitoring of biomass and growth-related protein production in aerobic fermentations).

The authors would like to express their gratitude to Ms. Idoia de Miguel and Ms. Elisa Martínez de Marañón for their help in the experimental work.

\section{References}

Budavari, S. 1996. The Merck index: An encyclopedia of chemicals, drugs and biologicals, 12th edition. Merck, Whitehouse Station, NJ.

Castrillo, J. I., de Miguel, I., Ugalde, U. O. 1995. Proton production and consumption pathways in yeast metabolism. A chemostat culture analysis. Yeast 11: 1353-1365.

Castrillo, J. I., Ugalde, U. O. 1993. Patterns of energy metabolism and growth kinetics of Kluyveromyces marxianus in whey chemostat culture. Appl. Microbiol. Biotechnol. 40: 386-393. 
Castrillo, J. I., Ugalde, U. O. 1994. A general model of yeast energy metabolism in aerobic chemostat culture. Yeast 10: 185-197.

Chattaway, T., Demain, A. L., Stephanopoulos, G. 1992. Use of various measurements for biomass estimation. Biotechnol. Prog. 8: 81-84.

Cooney, C. L., Wang, H. Y., Wang, D. I. C. 1977. Computer-aided material balancing for prediction of fermentation parameters. Biotechnol. Bioeng. 19: 56-67.

Fiechter, A., Käppeli, O., Meussdoerffer, F. 1987. Batch and continuous culture, pp. 99-129. In: A. H. Rose, and J. S. Harrison (eds.), The yeasts, vol.2, 2nd edition. Academic Press, London.

Flikweert, M. T., van der Zanden, L., Janssen, W. M. Th., Steensma, H. Y., van Dijken, J. P., Pronk, J. T. 1996. Pyruvate decarboxylase: An indispensable enzyme for growth of Saccharomyces cerevisiae on glucose. Yeast 12: 247-257.

van Gulik, W. M., Heijnen, J. J. 1995. A metabolic network stoichiometry analysis of microbial growth and product formation. Biotechnol. Bioeng. 48: 681-698.

Herbert, D. 1976. Stoichiometric aspects of microbial growth, pp. 1-30. In: A. C. R. Dean, D. C. Ellwood, C. G. T. Evans, and J. Melling (eds.), Continuous culture 6: Applications and new fields. Ellis Horwood Limited, UK.

Huth, J., Blasig, R., Werner, S., Mueller, H. G. 1990a. The proton extrusion of growing yeast cultures as an on-line parameter in fermentation processes: Determination of biomass production and substrate consumption in batch experiments with Candida maltosa EH15D. J. Basic Microbiol. 30(7): 481-488.

Huth, J., Werner, S., Mueller, H. G. 1990b. The proton extrusion of growing yeast cultures as an on-line parameter in fermentation processes: Quantitative determination of growth from milligram amounts of substrate in a minimized fed-batch fermentation apparatus. J. Basic Microbiol. 30(7): 489-497.

Huth, J., Werner, S., Mueller, H. G. 1990c. The proton extrusion of growing yeast cultures as an on-line parameter in fermentation processes: Ammonia assimilation and proton extrusion are correlated by an 1:1 stoichiometry in nitrogen-limited fed-batch fermentations. J. Basic Microbiol. 30(8): 561-567.

Ishizaki, A., Tripetchkul, S., Tonokawa, M., Shi, Z. P., Shimizu, K. 1994. $\mathrm{pH}$-mediated control methods for continuous ethanol fermentation using Zymomonas mobilis. J. Ferment. Bioeng. 77(5): 541-547.

Iversen, J. J. L., Thomsen, J. K., Cox, R. P. 1994. On-line growth measurements in bioreactors by titrating metabolic proton exchange. Appl. Microbiol. Biotechnol. 42: 256-262.

de Jong-Gubbels, P., Vanrolleghem, P., Heijnen, S., van Dijken, J. P., Pronk, J. T. 1995. Regulation of carbon metabolism in chemostat cultures of Saccharomyces cerevisiae grown on mixtures of glucose and ethanol. Yeast 11: 407-418.

Kotyk, A. 1989. Proton extrusion in yeast, pp. 592-603. In: S. Fleischer, and B. Fleischer (eds.), Methods in enzymology, vol. 174 (Biomembranes, Part U). Academic Press, New York.

Large, P. J. 1986. Degradation of organic nitrogen compounds by yeasts. Yeast 2: 1-34.

Larsson, C., von Stockar, U., Marison, I., Gustafsson, L. 1993. Growth and metabolism of Saccharomyces cerevisiae in chemostat cultures under carbon-, nitrogen-, or carbon- and nitrogen-limiting conditions. J. Bacteriol. 175: 4809-4816.

Miller, G. L. 1959. Use of dinitrosalicylic acid reagent for determination of reducing sugar. Anal. Chem. 31: 426-428.

Ohta, K., Hamada, S., Nakamura, T. 1993. Production of high concentrations of ethanol from inulin by simultaneous saccharification and fermentation using Aspergillus niger and Saccharomyces cerevisiae. Appl. Environ. Microbiol. 59: 729-733.

Oura, E. 1972. The effect of aeration on the growth energetics and biochemical composition of baker's yeast. Ph.D. thesis, University of Helsinki, Finland.

Phaff, H. J., Miller, M. W., Mrak, E. M. 1978. The life of yeasts. Nutrition and growth, 2nd edition, pp. 163-182. Harvard University Press, Boston, MA.

Pons, M. N., Garrido-Sanches, N., Engasser, J. M. 1989. Observability by pH in bioprocesses, pp. 227-231. In: N. M. Fish, R. I. Fox, and N. F. Thornhill (eds.), Computer applications in fermentation technology: Modelling and control of biotechnological processes. Elsevier Applied Science, London.

Postma, E., Verduyn, C., Scheffers, W. A., van Dijken, J. P. 1989. Enzymic analysis of the Crabtree effect in glucose-limited chemostat culture of Saccharomyces cerevisiae. Appl. Environ. Microbiol. 55: 468-477.

Roels, J. A. 1980. Application of macroscopic balances to microbial metabolism. Biotechnol. Bioeng. 22: 2457-2514.

Roos, W., Luckner, M. 1984. Relation between proton extrusion and fluxes of ammonium ions and organic acids in Penicillium cyclopium. J. Gen. Microbiol. 130: 1007-1014.

San, K.-Y., Stephanopoulos, G. 1984. Studies on on-line bioreactor identification. IV. Utilization of $\mathrm{pH}$ measurements for product estimation. Biotechnol. Bioeng. 26: 1209-1218.

Shioya, S. 1989. Measurement of biological reaction rates using advanced pH control systems, pp. 15-22. In: N. M. Fish, R. I. Fox, and N. F. Thornhill (eds.), Computer applications in fermentation technology: Modelling and control of biotechnological processes. Elsevier Applied Science, London.

Siano, S. A. 1995. On the use of the $\mathrm{pH}$ control reagent addition rate for fermentation monitoring. Biotechnol. Bioeng. 47: 651-665.

Sigler, K., Höfer, M. 1991. Mechanisms of acid extrusion in yeast. Biochim. Biophys. Acta 1071: 375-391.

Sonnleitner, B., Käppeli, O. 1986. Growth of Saccharomyces cerevisiae is controlled by its limited respiratory capacity: Formulation and verification of a hypothesis. Biotechnol. Bioeng. 28:927-937.

Sousa, M. L., Teixeira, J. A., Mota, M. 1994. Comparative analysis of ethanolic fermentation in two continuous flocculation bioreactors and effect of flocculation additive. Bioprocess Eng. 11: 83-90.

Stafford, K. 1986. Continuous fermentation, pp. 137-151. In: A. L. Demain, and N. A. Solomon (eds.), Manual of industrial microbiology and biotechnology. American Society for Microbiology, Washington, DC.

Stephanopoulos, G. 1986. Application of macroscopic balances and bioenergetics of growth to the on-line identification of biological reactors. pp. 332-349. In: H. C. Lim, and K. Venkatasubramanian (eds.), Biochemical engineering IV, vol. 469, Annals of the New York Academy of Sciences. New York Academy of Sciences, NY.

Stryer, L. 1995. Biochemistry, 3rd edition. W. H. Freeman and Co., NY.

Verduyn, C. 1992. Energetic aspects of metabolic fluxes in yeasts. Ph.D. thesis, Delft University of Technology, The Netherlands.

Verduyn, C., Postma, E., Scheffers, W. A., van Dijken, J. P. 1992. Effect of benzoic acid on metabolic fluxes in yeasts: A continuous-culture study on the regulation of respiration and alcoholic fermentation. Yeast 8: 501-517.

Verduyn, C., Stouthamer, A. H., Scheffers, W. A., van Dijken, J. P. 1991. A theoretical evaluation of growth yields of yeasts. Ant. van Leeuwenhoek 59: 49-63. 